\title{
Two independent effects of variation in intertrial interval upon leverpress avoidance learning by rats*
}

\author{
R. G. M. MORRIS $\dagger$ \\ Laboratory of Experimental Psychology, University of Sussex, Brighton, England
}

\begin{abstract}
Variation in the intertrial interval (ITI) preceding a given trial is shown to have an independent and opposite effect upon leverpress avoidance performance to that caused by variation in ITI after a trial. This finding accounts for the opposite effect of overall ITI upon leverpress avoidance to its effect upon one-way avoidance without recourse to an associative explanation. The implications of this finding for recent discussions of response constraints upon avoidance learning is discussed.
\end{abstract}

The experiment described in this paper suggests that variation in intertrial interval (ITI) has independent associative and nonassociative effects upon leverpress avoidance performance. Identification of these separate effects, which are normally confounded in experiments that vary only overall ITI, is of interest for two main reasons.

First, recognition of this possibility may provide a means of resolving the discrepancy that presently exists between experiments showing that lengthening ITI improves both one-way (see Denny, 1971) and shuttlebox (Brush, 1962; Weisman, Denny, \& Zerbolio, 1967) avoidance performance but worsens leverpress (Cole \& Fantino, 1966; Pearl, 1963; Pearl \& Fitzgerald, 1966) and wheel-turn (Anderson \& Nakamura, 1964) avoidance. Resolution of this discrepancy is of some importance, given the recent interest in the role of ITI in the reinforcement of avoidance behavior (Bolles \& Grossen, 1970; Denny, 1971; Weisman \& Litner, 1971, 1972).

Second, further understanding of how avoidance learning parameters influence the performance of different avoidance responses $\left(R_{a} s\right)$ may throw light on why these $R_{a} s$ are learned at widely differing rates. The present experiment focuses specifically on the question of whether variation in ITI has any associative effect on leverpress avoidance performance at all comparable to the known associative effects of ITI upon other $R_{a} s$ (see Denny, 1971).

The basic idea was to try to partial out the effects upon avoidance probability of variation in ITI preceding a trial from the effects of variation in ITI after a trial. To do this, a within-S design was employed in which rats received a sequence of trials separated, according to a Gellerman sequence, by a short or a long ITI. Two discriminable warning signals (WSs) were used, each predicting one or the other ITI with assignment to WSs

*This work was supported by a grant from the Science Research Council and formed part of a D Phil thesis submitted to the University of Sussex. I am grateful to N. S. Sutherland for his provision of facilities and to M. S. Halliday for his advice and assistance.

†The author is now the Addison $J$. Wheeler Research Fellow at the Department of Psychology, University of Durham, South Road, Durham, DH1 3LE, United Kingdom. to ITIs strictly counterbalanced across Ss. This sequencing arrangement allows measures of avoidance performance as a function of either predicted ITI or preceding ITI to be obtained separately.

Since trials predicting a particular ITI were preceded equally often by trials predicting a given ITI, any effect of predicted ITI on probability of $R_{a}$ is independent of any preceding ITI effect. However, this independence does not necessarily hold the other way around. Avoidance performance on a given trial is sometimes influenced by whether or not a $R_{a}$ or an escape response $\left(R_{e}\right)$ occurred on the preceding trial. Emergence of a predicted ITI effect will inevitably insure that trials preceded by a short or long ITI are also differentially preceded by different $R_{a}$ probabilities on the preceding trial. This confounding will then result in an apparent preceding ITI effect which actually has nothing to do with the differing ITIs. Fortunately, it is possible to assess whether any preceding ITI effect is real or artifactual by simply calculating the appropriate sequential avoidance statistics and then deriving the expected value of an artifactual effect. This is described later.

\section{METHOD}

\section{Subjects}

The Ss were 24 naive female rats of the Lister strain, born and bred at the Sussex University Animal House. They were approximately 90 days of age, weighed between 200 and $250 \mathrm{~g}$, and were housed individually and maintained on ad lib food and water.

\section{Apparatus}

Three identical rat boxes were used. These measured $25 \times 25 \times 25 \mathrm{~cm}$ and were constructed of aluminum. The floor consisted of 11 stainless steel bars, $0.63 \mathrm{~cm}$ in diam. A small stainless steel lever, requiring $10 \mathrm{~g}$ force for closure, was mounted centrally in one end wall at a height of $5.0 \mathrm{~cm}$. A 3-ohm speaker was mounted externally above the lever. Access to the boxes was via a hinged Perspex ceiling. Electric shock could be delivered to the grid bars, side walls, and lever from Grason-Stadler scramblers (Model E1064GS) set at an intensity of $0.8 \mathrm{~mA}$. Continuous or discontinuous $(3 \mathrm{cps})$ white noise stimuli were delivered via the loudspeaker in each chamber at an intensity of $90 \mathrm{~dB}$ against a background noise intensity of approximately $70 \mathrm{~dB}$. 


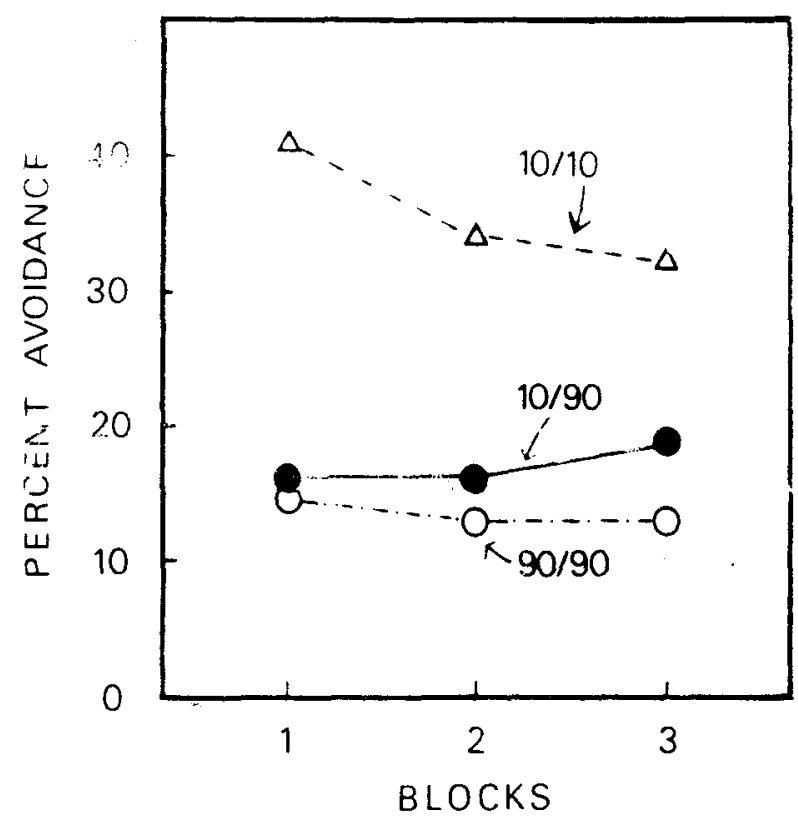

Fig. 1. The overall percent avoidance of the three groups across the three blocks of training trials.

All stimulus presentations and measurements of responding were controlled on-line using an Elliot 4130 computer.

\section{Procedure}

The Ss were randomly assigned to one of three groups, 12 rats being placed in Group 10/90 and 6 rats in each of Groups 10/10 and 90/90. The experiment was run in two replications, with half of the Ss of each group running in each replication.

All Ss were trained to avoid by the method of emergence (Solomon \& Brush, 1962). In this procedure, a WS preceded shock onset by $10 \mathrm{sec}$ until terminated by a leverpress response. After $10 \mathrm{sec}$, discontinuous shock pulses came on, each lasting $0.5 \mathrm{sec}$ (inescapable), separated by 1.5 -sec intervals. Responses occurring prior to shock onset were classified as $R_{2} s$, while those occurring after the start of the train of shocks were classified as $\mathrm{R}_{\mathrm{e}} \mathrm{s}$. All Ss were run for six sessions, with 41 trials per session.

The groups differed only with respect to the duration and sequence of ITIs between trials, this being timed from the moment a response occurred on one trial to WS onset on the succeeding trial. Ss in Group 10/90 received an intermixed sequence (Gellerman) of 10- and 90-sec ITIs, with half of the Ss in each replication having the continuous noise WS cueing the succeeding 10-sec ITIs and the discontinuous noise cueing the succeeding 90-sec ITIs. This arrangement was reversed for the remaining Ss of this group. Ss of Groups 10/10 and $90 / 90$ received an identical sequence of the WSs to those of Group $10 / 90$ but separated by a 10- or 90 -sec ITI between all of the trials, respectively. The intertrial periods themselves were not cued for any of the groups. Intertrial responding was permitted but went unrecorded.

The Gellerman sequence of ITIs was varied on successive sessions and the ITI following the first trial of the session changed, so that there would always be 20 trials followed by each ITI and 20 trials preceded by each ITI per session. Estimates of $R_{a}$ probability as a function of preceding and predicted ITI are derived from these $\mathbf{4 0}$ trials.

\section{RESULTS}

In view of the poor level of performance by all groups, typical of leverpress avoidance by rats, pairs of successive sessions were combined into 80 -trial blocks for purposes of analysis.

\section{Overall Avoidance Performance}

The overall avoidance performance by the three groups over these three blocks of trials is shown in Fig. 1. The data appear to replicate the now well documented inverse relationship between overall mean ITI and avoidance probability for leverpress avoidance (Cole \& Fantino, 1966; Pearl, 1963; Pearl \& Fitzgerald, 1966).

A formal analysis of variance of these data indicated that the main groups effect approached but failed to quite reach significance $(F=3.08, d f=2 / 18$, $.10>p>.05)$. No other effects or interactions were significant, i.e., replications, blocks, type of WS.

\section{Preceding ITI}

The probability of avoidance as a function of preceding ITI by the Ss of Group 10/90 is shown in Fig. 2. Avoidance probability is clearly higher after the short ITI.

An analysis of variance of these data confirmed that $\mathrm{R}_{\mathrm{a}}$ probability was higher after the shorter ITI $(\mathrm{F}=14.49, \mathrm{df}=1 / 10, \mathrm{p}<.005) . \mathrm{R}_{\mathrm{a}} \mathrm{s}$ were almost twice as frequent after the short ITI as after the long ITI at the outset of training, and 11 of the 12 Ss showed this preceding ITI effect (with one $S$ responding equally often after each ITI) during the first block of trials. There was some indication in the individual $S$ data of a diminution in the size of the effect toward the end of training, but this was not significant.

\section{Predicted ITI}

A quite different picture is clear in Fig. 3 , showing $R_{a}$ probability as a function of predicted ITI. The long ITI supported better avoidance performance, particularly toward the end of training.

An analysis of variance of these data revealed a significant effect of predicted ITI $(F=12.02, \mathrm{df}=1 / 8$,

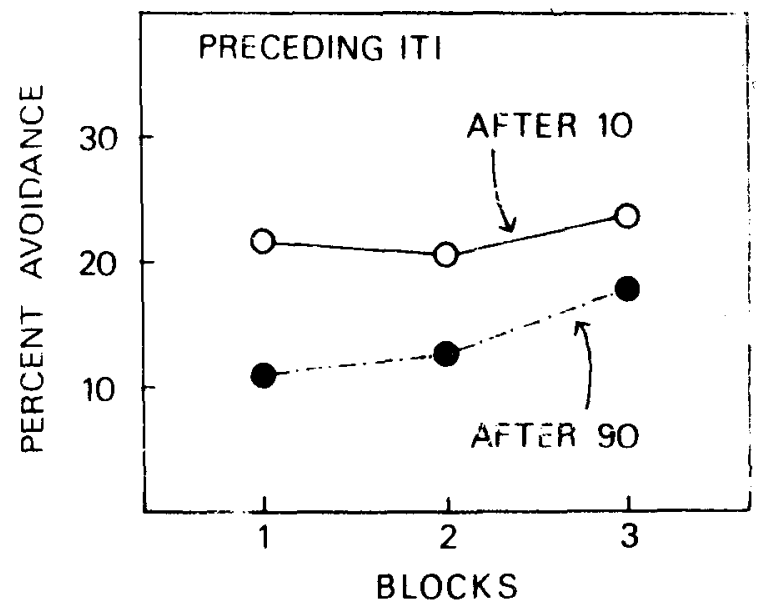

Fig. 2. The mean percent avoidance of Group $10 / 90$ on trials which followed either a 10 - or $90-\sec$ ITI. 
$\mathrm{p}<.01$ ). Although the effect appeared to grow over blocks, the Predicted ITI by Blocks interaction did not approach significance $(\mathrm{F}<1)$. As with the preceding ITI effect, the mean performance was mirrored in the individual $S$ data, with 10 out of 12 Ss showing the predicted ITI effect during the final block of training trials.

Independence of the Predicted and Preceding ITI Effects

The apparent emergence of the preceding ITI effect before the predicted ITI effect strongly suggests that the two effects are independent. This is shown formally in the data of Fig. 4. The probability of a $R_{a}$ given a $R_{a}$ on the previous trial $\left[P\left(R_{a} / R_{a}\right)\right]$ is higher than $\left[P\left(R_{a} / R_{e}\right)\right]$, an observation confirmed in a formal analysis of variance of these sequential avoidance statistics $(F=9.96$, $\mathrm{df}=1 / 11, \mathrm{p}<.025)$. Since $(1) \mathrm{R}_{\mathrm{a}} \mathrm{s}$ are more frequent on trials predicting a long ITI and (2) $R_{\mathbf{a}} s$ are more frequent after $R_{a} s$ than after $R_{e} s$, it follows that (3) $R_{a} s$ should also be more frequent on trials preceded by a long ITI. But because (4) the obtained preceding ITI effect actually takes the opposite sign, it follows that (5) the preceding ITI effect must be real and not artifactual.

\section{DISCUSSION}

These data indicate that variation in ITI has two independent and opposite effects upon leverpress avoidance probability.

The preceding ITI effect is almost certainly nonassociative. While it is possible that the effect is dependent upon the animals having learned to predict when the trial is to start, which would presumably be easier at short ITIs, the early emergence of the preceding ITI effect makes this unlikely (Black \& Carlson, 1959). The superiority of shorter preceding ITIs may be caused by a variety of factors, including elevated pretrial response rate (Pearl \& Fitzgerald, 1966; but see Cole \& Fantino, 1966), a higher momentary motivational level that decays with time over the ITI, or greater physical

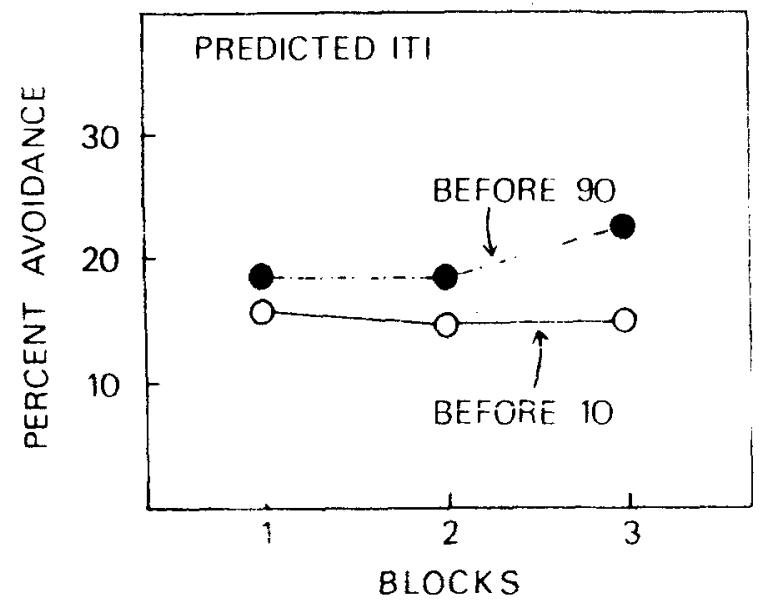

Fig. 3. The mean percent avoidance of Group 10/90 on trials which preceded either a 10- or 90-sec ITI.

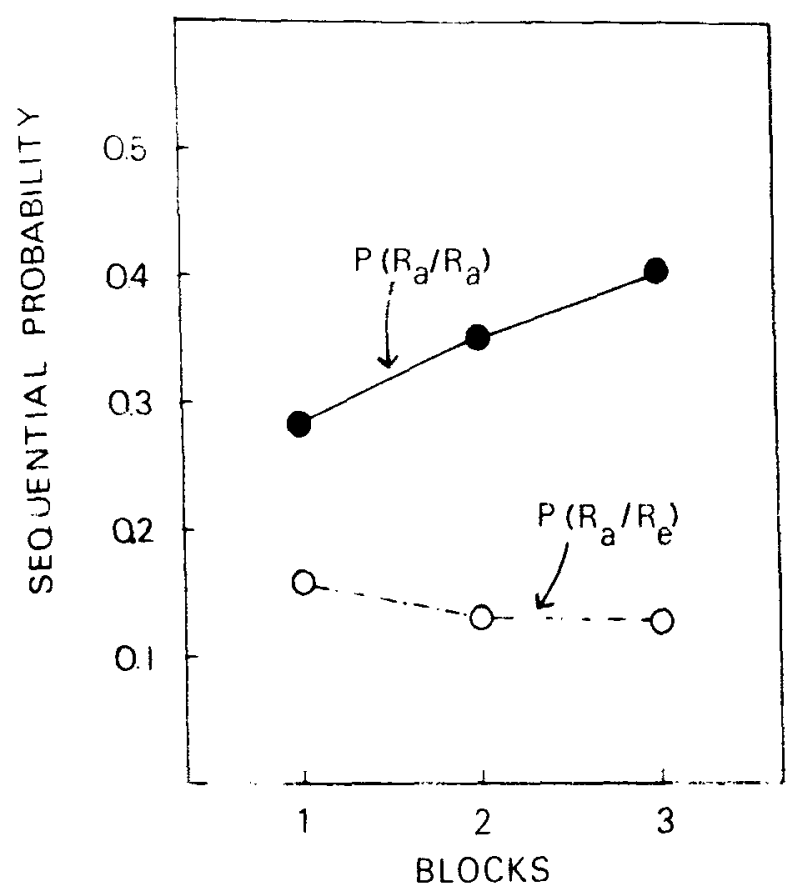

Fig. 4. Estimates of $P\left(R_{a} / R_{a}\right)$ and $P\left(R_{a} / R_{e}\right)$ derived from the data of Group 10/90. It is possible to derive the expected "artifactual" preceding ITI effect from knowledge of (1) the effect of predicted ITI and (2) the relative magnitude of these two sequential avoidance statistics. As described in the text, the sign of the obtained preceding ITI effect is opposite to that which would be expected if it were artifactual.

proximity of the rat to the lever at short ITIs. This experiment does not distinguish among these alternatives.

The presence of the preceding ITI effect early in training, its direction of inequality, and its magnitude all suggest that the main effect of variation in overall ITI in the leverpress situation is a consequence of variation in the ITI preceding a trial. If this is so, the inverse relationship between overall ITI and leverpress $R_{a}$ probability represents no embarrassment to those theories of avoidance learning which emphasize the role that long ITIs play in the reinforcement process (e.g., Denny, 1971; Weisman \& Litner, 1971). It is, of course, the case that this inverse relationship was not quite significant in the overall $R_{a}$ performance of this study. However, the presence here of a clear trend closely paralleling the significant findings of each of the three previous experiments demonstrating this inverse relationship (Cole \& Fantino, 1966; Pearl, 1963; Pearl \& Fitzgerald, 1966) probably constitutes sufficient evidence for this argument.

In fact, the demonstrated existence of a predicted ITI effect represents further support for these theories. A predicted ITI effect cannot be explained by Brush's (1962) notion that ITI effects are mediated largely by differential extinction of fear to apparatus cues, since the short and long ITI periods were not accompanied by discriminable cues. Moreover, Weisman and Litner 
(1971) were unable to find any effect of ITI upon excitatory fear conditioning. There is, therefore, no empirical basis for presuming that the two WSs in the present experiment were accompanied by different "fear gradients" following their offset as a function of the succeeding ITI that each WS cued. In short, the predicted ITI effect cannot be explained by a two-process model that makes reference solely to excitatory fear conditioning. A possible explanation of the effect is to suppose that the rats discriminated interoceptive response-associated feedback present after one WS from that present after the other WS. This feedback stimulation might then have developed differential fear-inhibiting properties as a function of the succeeding ITI (Weisman \& Litner, 1971) and, in turn, led to differential avoidance performance in each of the two WSs. However, this interpretation is not demanded by the data, which are also broadly consistent with relaxation theory (Denny, 1971).

Over the course of a series of papers (Bolles, 1970, 1971; Bolles \& Grossen, 1969; Bolles, Stokes, \& Younger, 1966), Bolles has argued that the speed at which avoidance learning proceeds is primarily determined by the similarity between $R_{a}$ and the animal's natural defense reactions. More recently, Bolles (1972) has gone on to argue that slowly learned $R_{a} s$ (such as leverpress avoidance) and quickly learned $R_{a} s$ (such as one-way avoidance) are learned in quite different ways. He bases his argument primarily on the now well established fact that these different $R_{a} s$ are not only learned at different rates but also learned at rates that are relatively unaffected by changes in a number of parameters hitherto thought critical to our understanding of avoidance learning (e.g., WS termination). However, this claim, and others concerning constraints upon the generality of the law of learning (e.g., Seligman, 1970), have not been backed up by demonstration that $R_{a} s$ which presumably enter into different kinds of associations can be dissociated with respect to the influence of different manipulable parameters (Black \& Young, 1972). The present experiment showing that poorly learned leverpress avoidance is sensitive to the associative effects of ITI in exactly the same way as quickly learned one-way avoidance (Denny \& Weisman, 1964) indicates that these two $R_{a} s$ cannot be dissociated with respect to this parameter, despite the fact that overall variation in ITI influences their performance in opposite ways. The result seems to warrant some caution before interpreting different rates of learning as evidence for different types of association.

\section{REFERENCES}

Anderson, N. H., \& Nakamura, C. Y. Avoidance decrement in avoidance conditioning. Journal of Comparative \& Physiological Psychology, 1964, 57, 196-204.

Black, A. H., \& Carlson, N. J. Traumatic avoidance learning: A note on intertrial interval responding. Journal of Comparative \& Physiological Psychology, 1959, 52, 759-760.

Black, A. H., \& Young, G. A. Constraints on the operant conditioning of drinking. In R. M. Gilbert and J. R. Millenson (Eds.), Reinforcement: Behavior analyses. New York: Academic Press, 1972.

Bolles, R. C. Species specific defense reactions and avoidance learning. Psychological Review, 1970, 77, 32-48.

Bolles, $R$. C. Species specific defense reactions. In F. R. Brush (Ed.), Aversive conditioning and learning. New York: Academic Press, 1971.

Bolles, R. C. The avoidance learning problem. In G. H. Bower (Ed.), The psychology of learning and motivation. Vol. 6. New York: Academic Press, 1972.

Bolles, R. C., \& Grossen, N. E. Effects of an informational stimulus on the acquisition of avoidance behavior in rats. Journal of Comparative \& Physiological Psychology, 1969, 68, 90-99.

Bolles, R. C., \& Grossen, N. E. Function of the CS in shuttlebox avoidance learning by rats. Journal of Comparative \& Physiological Psychology, 1970, 70, 165-169.

Bolles, R. C., Stokes, L. N., \& Younger, M. S. Does CS-termination reinforce avoidance behavior? Journal of Comparative \& Physiological Psychology, 1966, 62, 201-207.

Brush, $F$. R. The effect of intertrial interval upon avoidance learning in the rat. Journal of Comparative \& Physiological Psychology, 1962, 55, 888-892.

Cole, M., \& Fantino, E. Temporal variables and trial discreteness. Psychonomic Science, 1966, 6, 217-218.

Denny, M. R. Relaxation theory and experiments. In F. R. Brush (Ed.), Aversive conditioning and learning. New York: Academic Press, 1971.

Denny, M. R., \& Weisman, R. G. Avoidance behavior as a function of the length of non-shock confinement. Journal of Comparative \& Physiological Psychology, 1964, 58, 252-257.

Pearl, J. Intertrial interval and acquisition of a lever-press avoidance response. Journal of Comparative \& Physiological Psychology, 1963, 56, 710-712.

Pearl, J., \& Fitzgerald, E. Better discriminated bar-press avoidance at $\mathbf{s h}^{\prime}$; intertrial intervals. Psychonomic Science, $1966,6,497-498$.

Seligman, M. E. P. On the generality of the laws of learning. Psychological Review, 1970, 77, 406-418.

Solomon, R. L., \& Brush, E. S. Experimentally derived conceptions of an xiety and aversion. Nebraska Symposium on Motivation, $1956,4,212-305$.

Weisman, R. G., Denny, M. R., \& Zerbolio, D. J. Discrimination based on differential non-shock confinement associated with long non-shock confinement periods. Journal of Comparative \& Physiological Psychology, 1967, 63, 34-38.

Weisman, R. G., \& Litner, J. S. Role of intertrial interval in Pavlovian differential conditioning of fear in rats. Journal of Comparative \& Physiological Psychology, 1971, 74, 211-218.

Weisman, R. G., \& Litner, J. S. The role of Pavlovian events in avoidance training. In R. A. Boakes and M. S. Halliday (Eds.), Inhibition and learning. London: Academic Press, 1972.

(Received for publication February 4, 1974; revision received April 2, 1974.) 